\title{
SISTEMAS DE DIACLASES E INFLUÊNCIA TECTÔNICA DA BORDA SUDESTE DA BACIA SEDIMENTAR DO PARNAÍBA: PARQUE NACIONAL SERRA DA CAPIVARA, BRASIL
}

\author{
Maria Emanuella Firmino Barbosa ${ }^{1}$ \\ Max Furrier ${ }^{2}$
}

\begin{abstract}
Resumo: O Parque Nacional Serra da Capivara com suas características geomorfológicas peculiares faz deste sítio um importante foco de estudo. Suas características geomorfológicas são herdadas do resultado de um tipo de clima muito mais úmido com o atual, além das atividades tectônicas cujo entendimento pormenorizado ainda se encontra distante, pois gerou uma série de esforços nas rochas sedimentares da Bacia do Parnaíba, o que resultou num intrigado sistema de diaclases de direções variadas e de importância relevante na evolução e configuração atual do relevo. A identificação das diaclases abre um novo caminho para o entendimento do relevo ruiniforme, muito comum nas bordas sul $e$ sudeste do parque, que é gerado pela tendência de infiltração das águas pluviais nessas diaclases, o que acentua o processo erosivo e esculpe formas peculiares. O fator tectônico, muitas vezes renegado ou subestimado na configuração do relevo brasileiro, começa a aflorar de maneira conspícua na comunidade geomorfológica brasileira e muitas das explicações sobre o modelado produzidas entre os anos de 1960 a 1990 começam a ser revistos sobre essa nova óptica.
\end{abstract}

Palavras-Chave: Tectônica; Diaclases; Parque Nacional da Serra da Capivara.

\section{FRACTURES SYSTEMS AND TECTONIC INFLUENCE OF THE SOUTHEAST EDGE OF PARNAÍBA SEDIMENTARY BASIN: SERRA DA CAPIVARA NATIONAL PARK, BRAZIL}

\begin{abstract}
The Serra da Capivara National Park with their peculiar geomorphological characteristics also make it an important focus of studies, once the refief of the area was the scene of activities done by the pre-historical populations who lived there and who registered the most varied daily activities through rupestral paintings. The geomorphological characteristics of the park are inherited from both a kind of much more humid climate, which lasted until approximately 10 thousand years ago, and from the tectonic activities, whose detailed explanation is far from being understood, for they generated a series of efforts in the sedimentary rocks of the Basin of Parnaiba that resulted in an intriguing system of fractures in various directions, often truncated, of relevant importance for the evolution and current configuration of the relief. The easy visualization of these fractures, through satellite images, aerial photographs, and field work, open a new path for understanding the ruiniform relief, which are common on the southern and south-eastern edges of the park and generated by the tendency of rainwater which percolated these fractures, causing accentuated processes of erosion and sculpting peculiar forms of incredible beauty that fascinate tourists and researchers from various parts of Brazil and the world. The tectonic factor, too often overlooked and underestimated in the configuration of Brazilian relief,

\footnotetext{
${ }^{1}$ Graduação em Geografia, Mestranda em Geografia do Programa de Pós-Graduação em Geografia UFPB/ CCEN - Campus I, Departamento de Geociências. Graduação em Tecnologia em Geoprocessamento (IFPB) - E-mail: mariaemanuellaf@gmail.com

${ }^{2}$ Graduação em Geografia, Mestrado em Geografia Física, Doutorado em Geografia Física, Professor do Programa de Pós-Graduação em Geografia UFPB/ CCEN - Campus I, Departamento de Geociências - E-mail: max.furrier@hotmail.com DOI: 10.7154/RDG.2012.0023.0011
} 
begins to emerge so conspicuously in the Brazilian geomorphology community and much of the understanding about patterned produced in the years of 1960 to 1990 are being revised under this new optics.

Key-Words: Tectonics; Joint; Serra da Capivara National Park.

\section{INTRODUÇÃO}

O Parque Nacional Serra da Capivara com suas características geomorfológicas peculiares faz deste sítio um importante foco de estudo. Suas características geomorfológicas são herdadas do resultado de um tipo de clima muito mais úmido que o atual, além das atividades tectônicas cujo entendimento pormenorizado ainda se encontra distante, pois gerou uma série de esforços nas rochas sedimentares da Bacia do Parnaíba, o que resultou num intrigado sistema de diaclases de direções variadas e de importância relevante na evolução e configuração atual do relevo.

As características ambientais particulares de grande interesse científico e turístico fazem do Parque Nacional Serra da Capivara uma unidade singular onde o relevo e sua evolução são peças chaves para a compreensão do complexo ambiente em questão.

O Parque Nacional Serra da Capivara encontra-se na justaposição de dois conjuntos geológicos: a depressão periférica da planície pré-cambriana do São Francisco e a bacia sedimentar paleozóica do Piauí-Maranhão Estes domínios geológicos sustentam dois domínios geomorfológicos distintos: os Planaltos e Chapadas da Bacia do Parnaíba e a Depressão Periférica Sertaneja e do São Francisco. Em função dessas características a área torna-se de significativa importância para o desenvolvimento de estudos geomorfológicos, pois o relevo local influencia na variedade paisagística, principalmente, na vegetação que depende dos fatores morfoclimáticos (NERES, et al. 2011).

A criação do Parque Nacional da Serra da Capivara teve dois objetivos direcionados à preservação de um ecossistema específico e de um dos mais importantes patrimônios culturais pré-históricos do mundo. As características marcantes na criação do parque foram de natureza cultural, ambiental e turística.

A identificação das diaclases abre um novo caminho para o entendimento do relevo ruiniforme, muito comum nas bordas sul e sudeste do parque, que é gerado pela tendência de infiltração das águas pluviais nessas diaclases, o que acentua o processo erosivo e esculpe formas peculiares. O fator tectônico, muitas vezes renegado ou subestimado na configuração do relevo brasileiro, começa a aflorar de maneira conspícua na comunidade 
geomorfológica brasileira e muitas das explicações sobre o modelado produzidas entre os anos de 1960 a 1990 começam a ser revistos sobre essa nova óptica.

\section{Localização da Área de Estudo}

O Parque Nacional da Serra da Capivara está localizado no sudeste do estado do Piauí, ocupando as áreas dos municípios de São Raimundo Nonato, João Costa, Brejo do Piauí e Coronel Dias, entre as coordenadas 8 26' 50" e 8ㅇ 54' 23" de latitude sul e 42으 19' 47" e 42은 45' 51" de longitude oeste. O parque ocupa uma área de 129,140 hectares e seu perímetros é de 214 km (Figura 1).

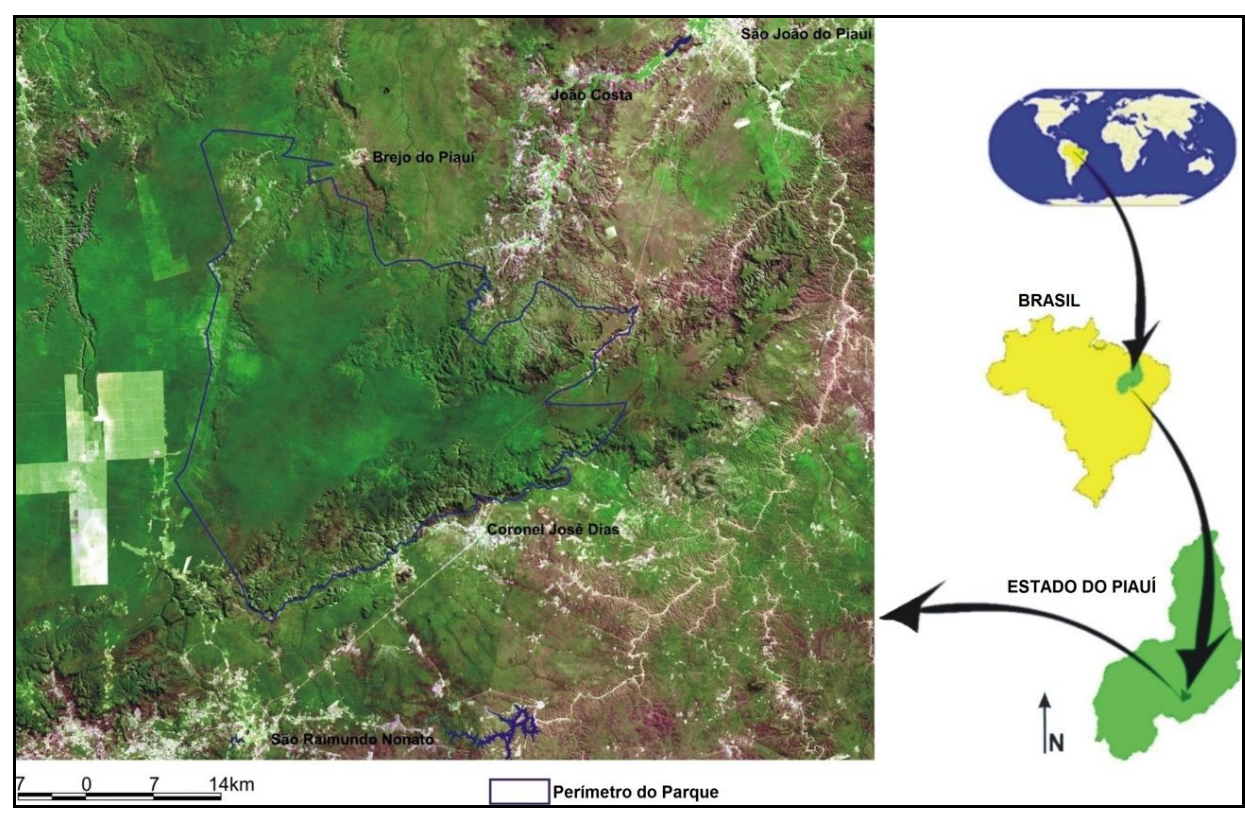

Figura 1 - Localização da área de estudo (Fonte: www.fumdham.org.br)

\section{Caracterização Geológica da Área de Estudo}

O parque se encontra em uma área limítrofe entre três grandes e distintos compartimentos geológicos: a bacia sedimentar do Parnaíba, a faixa orogênica Rio Preto e o Cráton do São Francisco. A primeira está representada no parque pelas rochas sedimentares do Grupo Serra Grande do Siluriano e das Formações Pimenteiras e Cabeças do Devoniano, além dos depósitos coluvio-eluvionares do Quaternário capeadoras. A faixa do Rio Preto se localiza no limite sudeste do parque, predominando rochas metamórficas do Neoproterozóico como: gnaisses, calcitas, micaxistos, metacalcários, além de intrusões de granito formando 
inselbergs. O cráton do são Francisco se localiza no limite sul do parque, onde predomina ortognaisses migmatíticos, tonalíticos / trondhjemíticos e granodiorítos, com enclaves máficos e restos de rochas da parte superior da crosta (Figura 2).

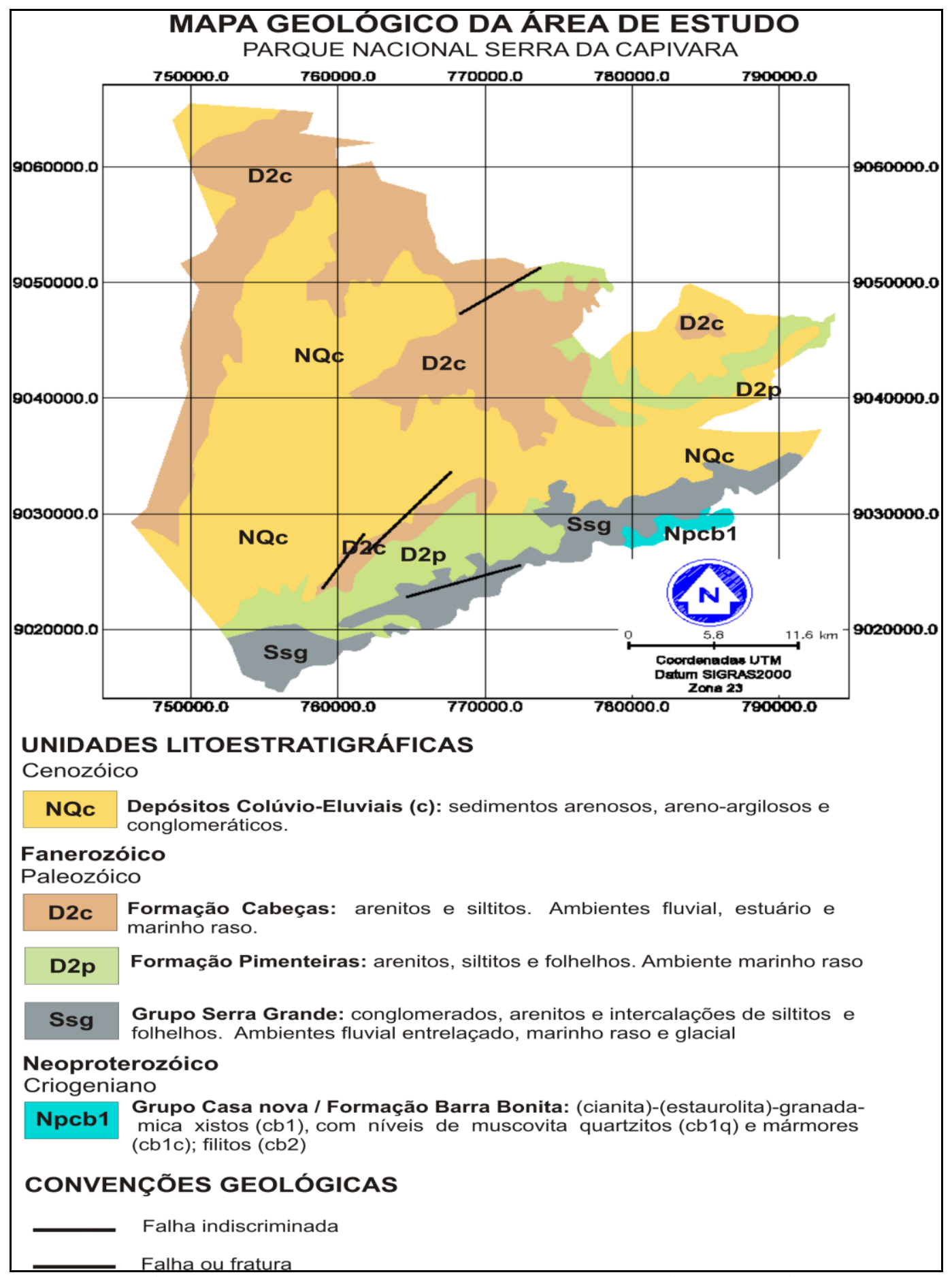

Figura 2 - Mapa Geológico do Parque Nacional da Serra da Capivara e adjacências (modificado de Brasil, 2006). 
Estes três compartimentos geológicos sustentam os compartimentos geomorfológicos também distintos: os altiplanos e mesetas da bacia sedimentar do Parnaíba e a depressão do agreste e São Francisco (Ross, 1985).

Nos limites sul e sudeste do Parque Nacional Serra da Capivara é formado por relevos do tipo cuesta, onde são visíveis as inclinações das camadas sedimentares em direção ao centro da bacia sedimentar. O relevo de cuesta em sua grande maioria foram esculpidas nos arenitos e conglomerados do Grupo Serra Grande e possuem desníveis altimétricos de 50 a $150 \mathrm{~m}$. nos pontos mais altos da área, a frente de cuesta, alcança altitudes de 50 a $150 \mathrm{~m}$. A evolução dos processos erosivos da bacia sedimentar do Parnaíba produz um relevo ruiniforme de impressionante beleza dando lugar a formações rochosas como a Pedra Furada, símbolo do parque (Figura 3).

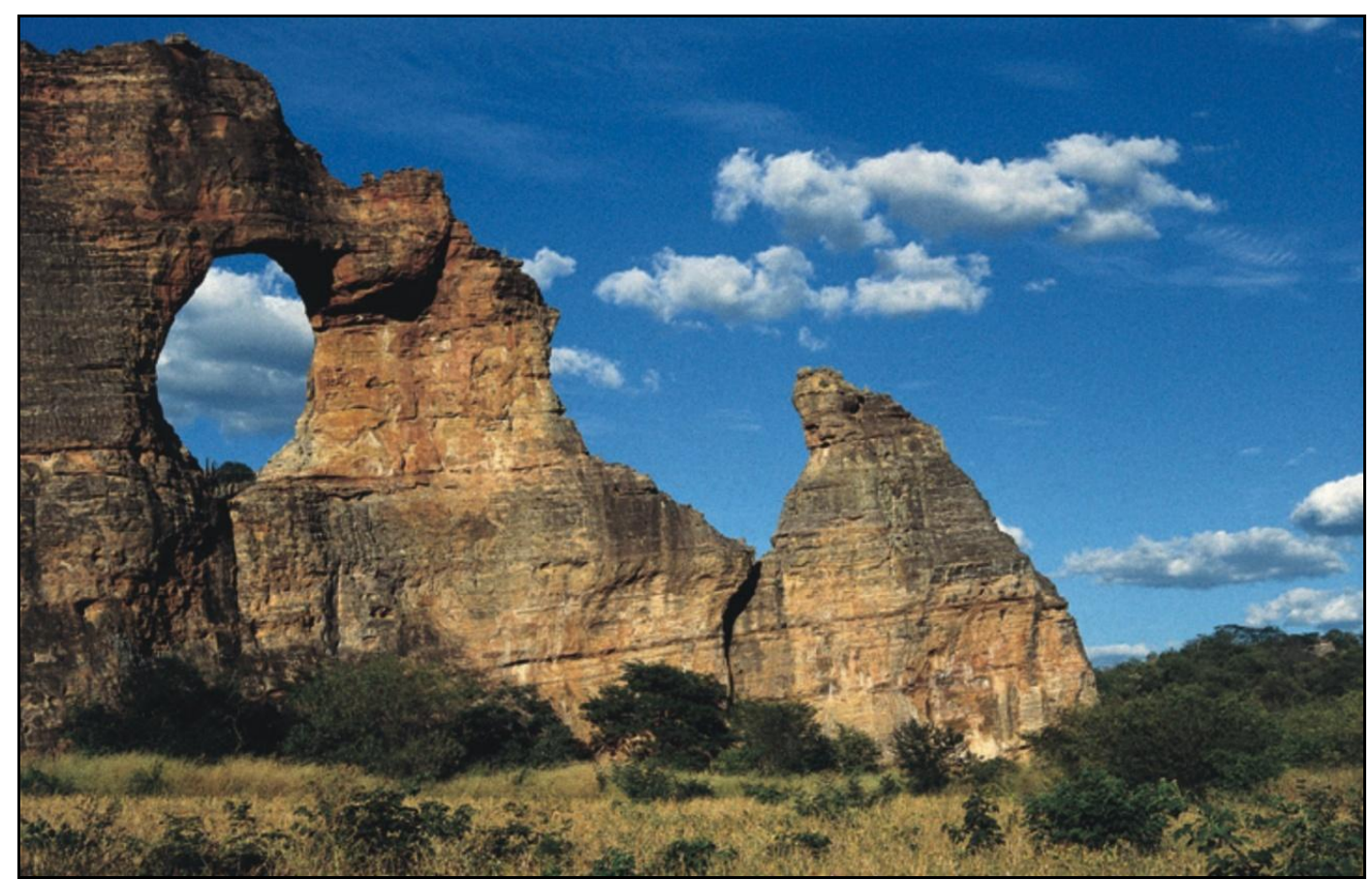

Figura 3 - Pedra Furada. Formação símbolo do parque (Foto: Max Furrier, 2008).

O maior setor da área de cobertura do parque prevalece um relevo reverso de cuesta de baixa inclinação, com direção para o centro da bacia sedimentar, é interrompida por escarpas de elevada inclinação esculpidas em arenitos da formação Cabeças, devido à erosão fluvial exercida principalmente por fluxos da Baixa do Lima e Toca da Onça em tempos de clima mais úmido. As escarpas encontradas nas proximidades do Baixa do Lima são denominadas localmente de "Serra Branca". A competência erosiva destes fluxos, atualmente intermitentes, foi em um período de clima mais úmido, muito mais intensa que a 
atual a ponto de erodir intensamente as rochas sedimentares formando escarpas com elevadas declividades. Esse clima mais úmido perdurou na região por 9.000 anos (Suguio, 1998), quando a vegetação local era caracterizada por uma flora similar a savana tropical do Brasil.

As diaclases de caráter tectônico encontradas principalmente nas bordas sul e sudeste do parque, influem de forma muito intensa no desenvolvimento de características morfológicas típicas. A questão relevante não é sua influencia na configuração dessas características, pois, com relação a isso não há duvidas, a grande questão que germina neste trabalho quanto à origem dessas características morfológicas sendo que esta última questão poderá ser desvendada nas próximas investigações e trabalhos a ser produzidos com este enfoque. Neste trabalho serão abordadas as localizações, direções, possíveis origens e algumas características típicas produzidas pelo dinamismo das águas que penetram nestas diaclases, colaborando de forma conspícua e determinante na evolução e configuração do relevo na área.

\section{MÉTODOS E TÉCNICAS}

Com o apoio de imagens obtidas pelo Google Earth (earth.google.com.br) de alta resolução foi possível corroborar as informações de campo, observando a Figura 4 pode-se observar a localização de todas as imagens capturadas no Google Earth. A partir da análise das imagens, cartas geológicas e topográficas foi possível identificar com precisão as fraturas desencadeadas por esforços tectônicos e suas respectivas direções principais não deixando dúvidas de sua influência determinante na composição e evolução do relevo ruiniforme nas bordas sul e sudeste do Parque Nacional Serra da Capivara.

O material cartográfico produzido nesse trabalho foi confeccionado com auxílio do software Spring 5.1.7. Todo o material construído foi gerado de forma automática a partir dos dados topográficos extraídos da imagem de radar Shuttle Radar Topography Mission (SRTM), possuindo uma resolução espacial de $90 \mathrm{~m}$, disponível no site http://srtm.csi.cgiar.org/SELECTION/inputCoord.asp. As coordenadas utilizadas foram UTM e o Datum SIRGAS2000. 


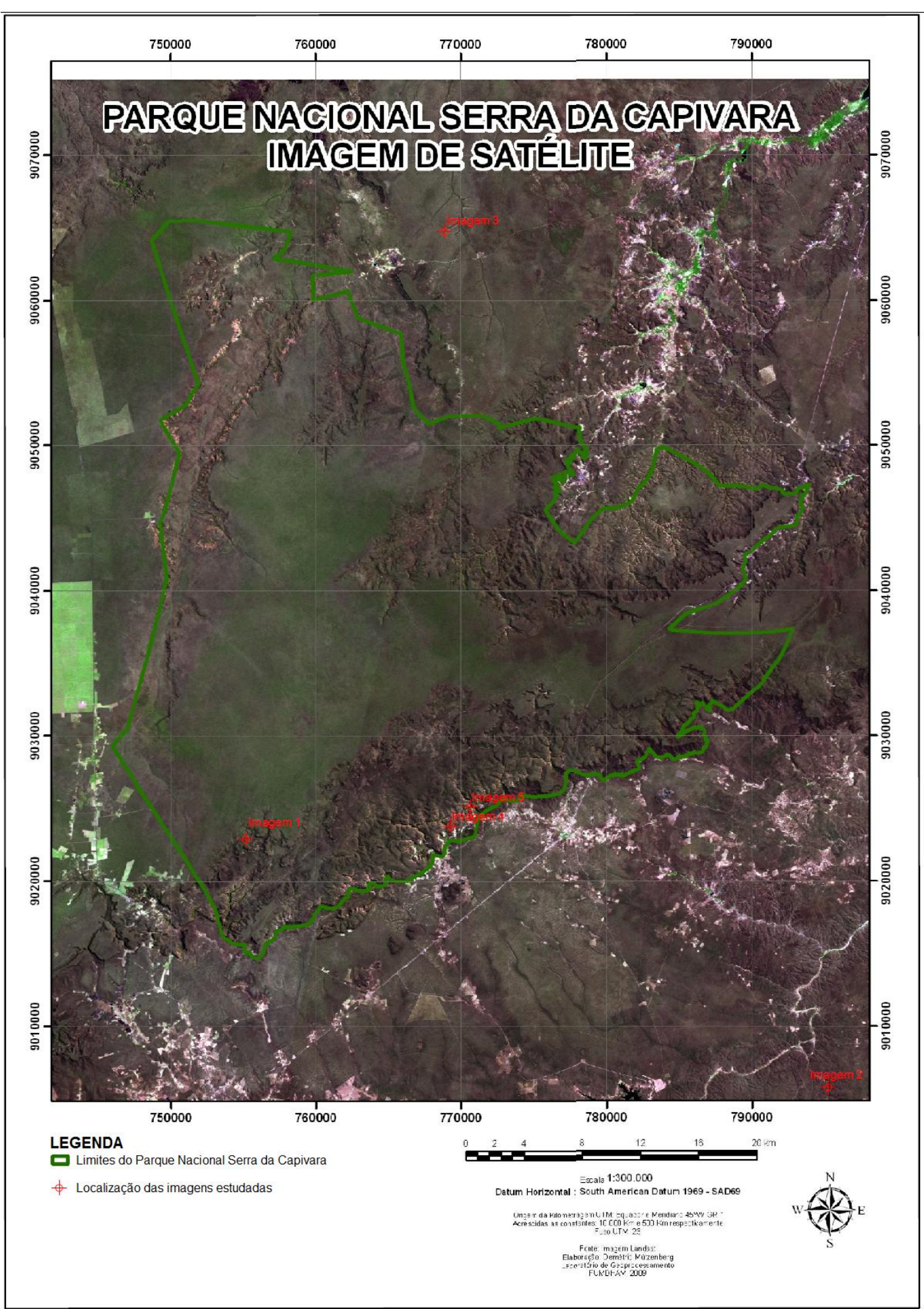

Figura 4 - Localização das imagens capturadas no Google Earth (modificado de FUMDHAM, 2009)

A partir do recorte da imagem SRTM da área do parque da Serra da Capivara, foi gerado um arquivo vetorial, esse arquivo consiste nas curvas de nível geradas a partir dos dados da imagem SRTM, a eqüidistância entre as curvas de nível foram de $50 \mathrm{~m}$, em seguida foi gerado um Modelo Digital de Elevação (MDE), a partir do MDE foram confeccionadas a grade 
triangular que serviu para a geração da carta de declividade e a grade retangular, que é utilizada para produzir a carta hipsométrica.

Para criação da carta clinográfica a primeira etapa a ser seguida foi a geração da Grade Triangular Irregular, Triangular Irregular Network (TIN), que mostra a quantidade dos dados, favorecendo uma análise mais quantitativa (Câmara et al. 2001). Os vértices do triângulo são geralmente os pontos amostrados da superfície. Essa modelagem, considerando as arestas dos triângulos, permite que as informações morfológicas importantes como as descontinuidades, representadas por feições lineares de relevo (cristas) e drenagem (vales), sejam consideradas durante a geração de uma grade triangular, possibilitando assim modelar a superfície do terreno preservando as feições geomórficas da superfície (Lopes et al. 2006).

Na produção do TIN, o modo de triangulação utilizado nesse trabalho foi o Delaunay, que favorece a criação de triângulos o mais próximo de equiláteros possível. A tolerância de isolinhas escolhida foi de 10 metros, distância entre pontos e isolinhas de 200 metros, a tolerância de linhas de quebra de 10 metros e triangulação da menor aresta de 2 metros. Esses valores numéricos foram adotados pelo fato das curvas de nível preexistentes possuírem equidistância de $10 \mathrm{~m}$, expondo um ótimo nível de precisão, além das dimensões reduzidas da área do Parque da Serra da Capivara, sendo assim necessários valores baixos para a obtenção de uma triangulação com fidelidade desejável para a representação da realidade.

Um ponto importante para a confecção da carta clinográfica foi a escolha das classes de declividade, que para o presente trabalho foram utilizadas as estabelecidas por Herz e De Biasi (1989) que atrelaram essas classes a limites utilizados internacionalmente, bem como a trabalhos desenvolvidos por institutos de pesquisas nacionais e leis vigentes no Brasil. Observar as classes de declividade em porcentagem e o seu equivalente em graus na Tabela 1.

Para confecção da carta hipsométrica as seguintes etapas foram seguidas: o arquivo vetorizado foi transferido para o software Spring 5.1.7, onde foi gerada uma grade retangular em formato raster e outro numérico. Ponderada por Cota e Quadrante, com resolução de 50 pixels. A etapa seguinte consistiu no processo de fatiamento das faixas de altitude, que no presente trabalho foram considerados intervalos de 50 em 50m (de 200 à $700 \mathrm{~m})$. 
Tabela 1 - Classes de declividade proposta por Herz e De Biasi (1989) em porcentagem e seus respectivos valores em graus.

\begin{tabular}{l|l}
\hline \multicolumn{2}{c}{ CLASSES DE DECLIVIDADE } \\
\hline EM PORCENTAGEM & EM GRAUS \\
$>12 \%$ & $<7,25 \circ$ \\
$12-30 \%$ & $7,25-17 \circ$ \\
$30-47 \%$ & $17-25 \circ$ \\
$47-100 \%$ & $25-45 \circ$ \\
$>100 \%$ & $>45 \circ$ \\
\hline
\end{tabular}

Na geração da grade retangular foi utilizado no presente estudo o interpolador: Média Ponderada por Cota e Quadrante, com potência de 2 metros. Esse interpolador foi escolhido, pois as curvas de nível e os pontos cotados já davam um ótimo nível de precisão, portanto, não sendo necessário um maior rebuscamento na malha retangular, salientando que o tamanho do arquivo utilizado nesse tipo de interpolador é relativamente pequeno, comparando com os outros interpoladores.

\section{RESULTADOS E DISCUSSÃO}

As diaclases são caracterizadas por fraturas parciais de um corpo em resposta a uma força aplicada (Suguio, 1999). As diaclases possuem direções variadas de acordo com as direções dos esforços aplicados, são de grande importância na evolução do relevo terrestre, devido aos pontos fracos de ataques da erosão (Guerra e Teixeira Guerra, 1997).

As diaclases, visíveis através de imagens de satélite, são predominantes nas rochas sedimentares do Grupo Serra Grande, porém existe também diaclases nas rochas sedimentares das Formações Pimenteiras e Cabeças. Por tanto, sobre o enfoque de idade litológica, as diaclases podem ser estendidas do siluriano ao devoniano, o que não oferece nenhuma precisão. São visíveis, também, as diaclases na formação quaternária capeadora, provavelmente reflexo de fraturas nas formações do siluriano e devoniano sotopostas.

Segundo Petri e Fúlfaro (1983), as forças atuantes nas bacias intracratonicas, como a do Parnaíba, têm sido descritas como predominantemente de tração, com base no conceito teórico de subsidência na superfície plana o que pode ocasionar esforços com o surgimento de diaclases.

Outra possibilidade está nos grandes traços estruturais de embasamento Pré-cambriano (falhas e zonas de ruptura), orientados nas direções NE-SW/E W que parecem condicionar os 
traços estruturais geral da bacia do Parnaíba, através de sucessivos períodos de reativação. Movimentos diferenciados de blocos através de fortes basculamentos bem como o desenvolvimento de anticlinais e sinclinais são características observadas com freqüência no registro geológico da bacia.

Parte do cráton do São Francisco mostra uma série de lineamentos topográficos no sentido E-W que poderiam estar eventualmente relacionadas às falhas com componente extensional associada ou mista associados à compressão E-W, oriunda de esforços que geram uma fase final de evolução das faixas de dobramento setentrionais vizinhos (SADOWSKI; CAMPANHA 2004).

As notáveis falhas de Patos e Pernambuco (Figura 5) condicionam bordas de bacias sedimentares e suas estruturas, supostamente, adentram pela bacia do Parnaíba, como também a falha inversa Senador Pompeu. Essas falhas foram reativadas durante e depois da abertura do atlântico e estão possivelmente relacionadas, não esta claro se formaram sincronicamente ou se eram falhas preexistentes reativadas posteriormente pelo tectonismo transcorrido (SADOWSKI; CAMPANHA, 2004). Não há dúvidas da influência destas falhas e de suas reativações posteriores na configuração e delineamento do relevo atual. As direções das fraturas encontradas no Parque Nacional Serra da Capivara parecem estar relacionadas às direções destes lineamentos que, provavelmente, aderem ao embasamento cristalino da bacia do Parnaíba.

Existe, a possibilidade que tais rupturas são atribuídas a tectônica cenozóica, trabalhos desenvolvidos recentemente em várias partes do território brasileiro e principalmente na região Nordeste geraram o conceito que a estabilidade tectônica da plataforma brasileira é relativa (SAADI et al., 2005).

Segundo Loczy e Ladeira (1980) existe uma grande possibilidade de que estas diaclases se originaram com as juntas de cisalhamento, como existe uma grande possibilidade de estarem relacionadas com falhas regionais, onde logo podem existir importantes alongamentos ao longo de sua direção. Quando os conjuntos de diaclases se entrelaçam com um ângulo alto formando um sistema em conjunto, colocadas sistematicamente sobre o eixo principal da formação, se consideram as fraturas e cisalhamento (LOCZY; LADEIRAS 1980). 


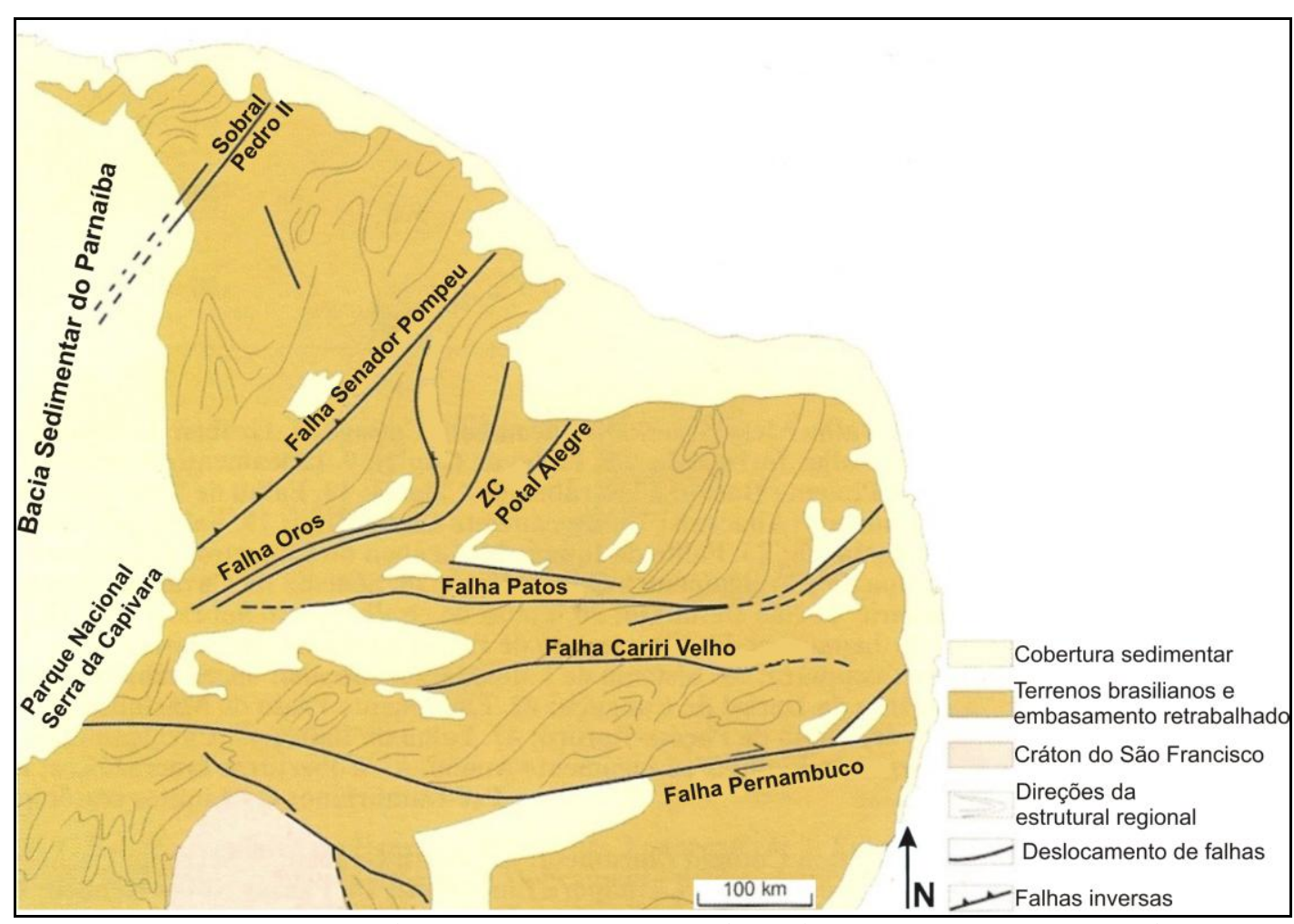

Figura 5 - Principais falhas da região nordeste (modificado de Brito-Neves, 1983).

A importância das cuestas encontradas no parque aparece claramente como uma função quase direta da importância relativa do levantamento das bordas, acompanhando a subsidência e os eixos da bacia e o levantamento do terreno Pré-cambriano na sua periferia. O desnível altimétrico também é muito mais pronunciado na parte sul do parque, com déficit total de até $300 \mathrm{~m}$. Em contraposição, na parte norte do parque, estas diferenças altimétricas tornam-se menos pronunciadas, não sendo superiores a $100 \mathrm{~m}$ e apresenta relevos escarpados em alguns pontos com morfologia mais homogênea (Figura 6).

A declividade das camadas sedimentares na direção do centro é elevada nas bordas sudeste do parque, expondo, também, as camadas sedimentares sobrepostas. As maiores elevações se encontram no centro sul do parque, onde os divisores de água mostram um maior número de cursos de águas na setor sudeste que termina por impulsionar os processos geomorfológicos nesta parte.

A carta de declividade mostra o evidente predomínio de relevo tabular na maioria do parque, com uma inclinação, predominante, inferior a 12\%. Também e claramente visível, a elevada inclinação encontrada na borda sudeste e leste no parque divergindo em outras partes do parque, principalmente, no sul, onde se encontram com relativa facilidade, 
declives superiores a 45 o vinculados a numerosas diaclases, verificados nesta parte (Figura 7).

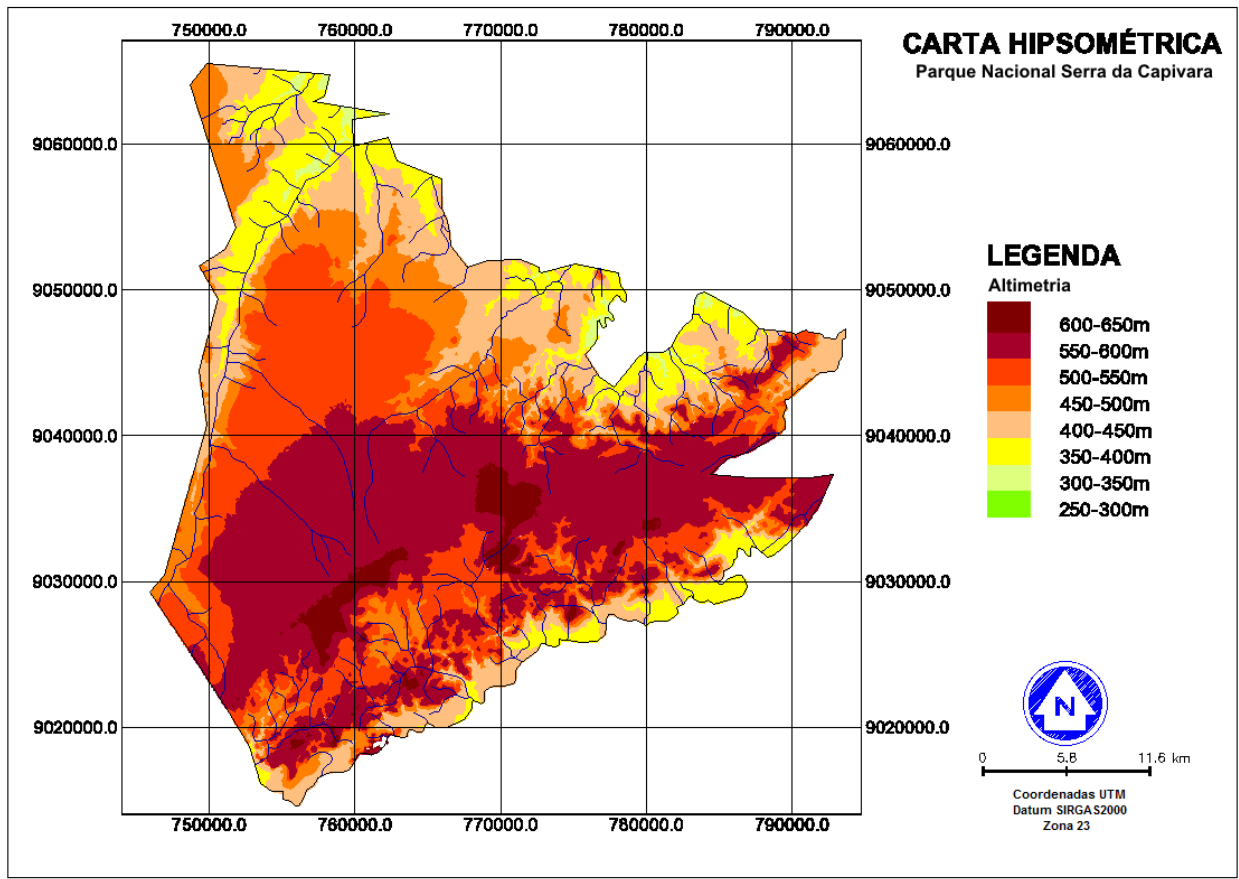

Figura 6 - Carta hipsométrica do Parque Nacional Serra da Capivara.

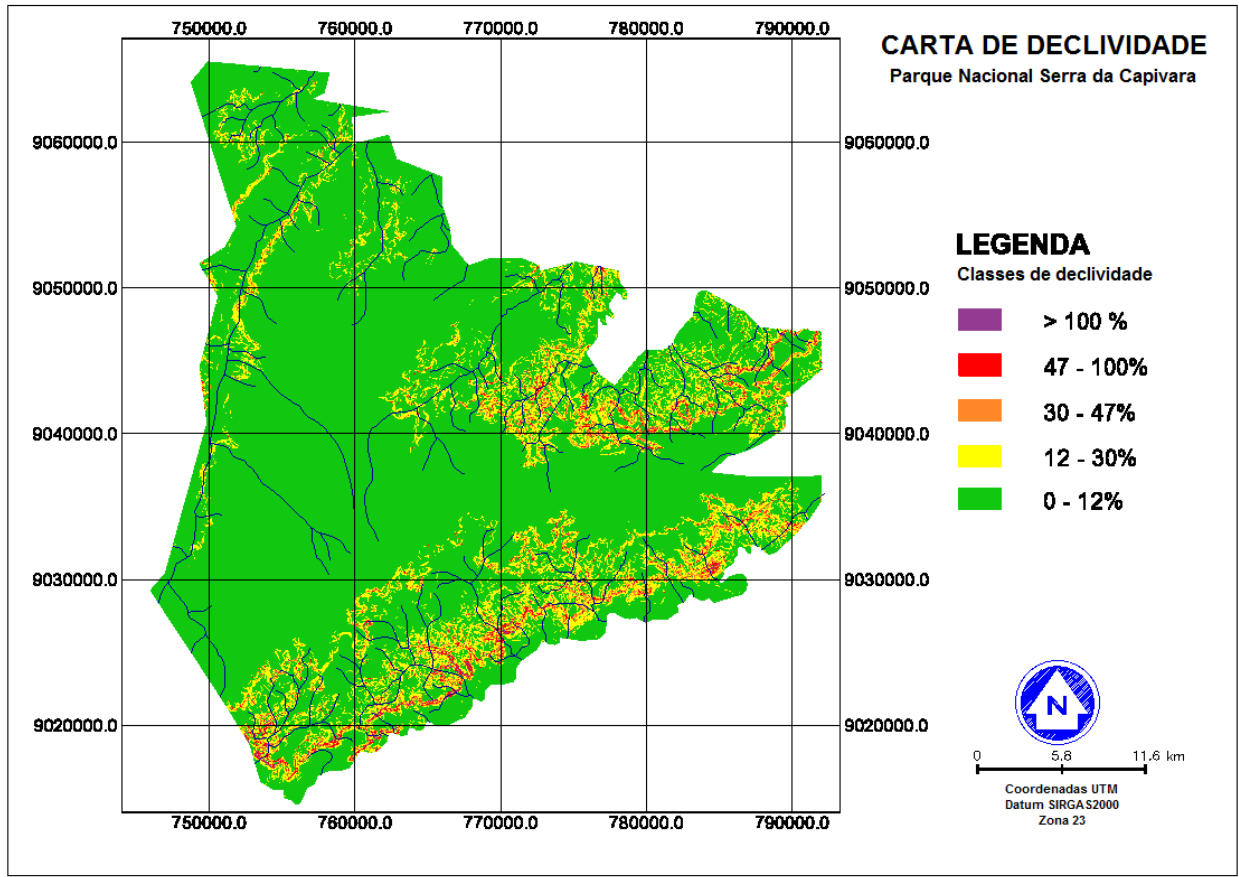

Figura 7 - Carta de Declividade do Parque Nacional Serra da Capivara.

Em períodos de chuvas intensas, ocorre a formação de numerosas cascatas na direção da parte inferior destas diaclases que formam fluxos turbulentos e com alta concentração de água impulsionando processos morfológicos, e por isso, muito diferentes dos processos que 
ocorrem em outras partes do parque onde a presença do relevo ruiniforme é insignificante ou inexistente.

No setor sul do parque, mais precisamente no sitio arqueológico "Toca das Pedrinhas Pintadas" (Figura 8) e arredores, se observa um nítid o sistema de diaclases com direção N-S, no setor oeste deste sitio, e com direção NNE-SSW no setor leste, cortando as cuestas esculpidas no Grupo Serra Grande (Figura 9).

Na sequência para nordeste, no entorno do sitio arqueológico "Toca dos Oitenta", se observa um conspícuo vale fluvial escavado em períodos de clima mais úmido, quando os rios eram mais caudalosos e, por tanto, com mais capacidade no processo de erosão fluvial. Através das imagens de satélite, se pode observar nesta área um intrigado sistema de diaclases com intersecções de outro sistema de diaclases com direções perpendiculares, com orientação N-S e NW-SE sugerindo esforços direcionados (Figura 9). Nestas intersecções, se pode observar o desenvolvimento de áreas mais abertas onde os processos erosivos foram mais intensos devido ao encontro das águas pluviais gerando forte turbulência e, por tanto maior capacidade erosiva.

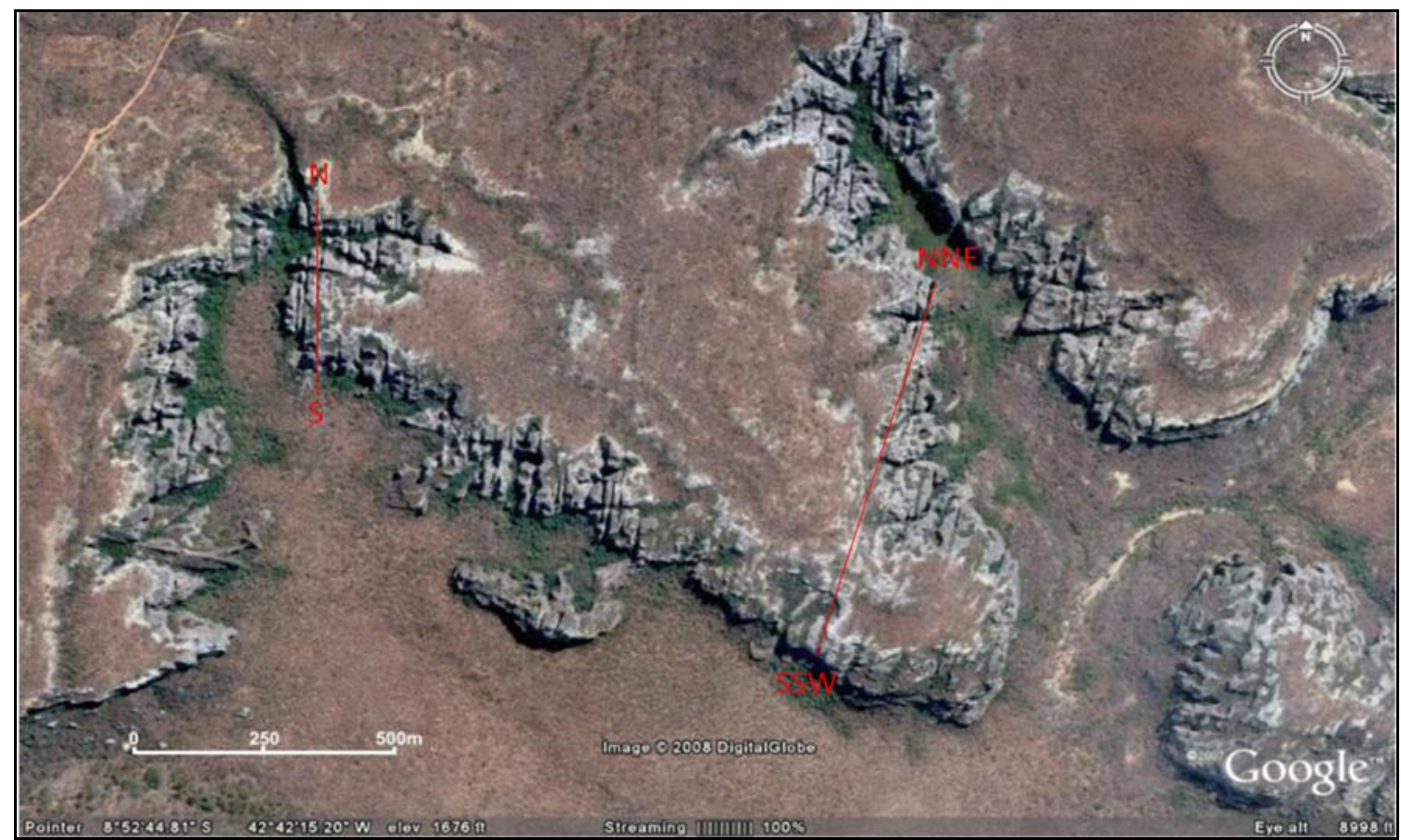

Figura 8 - Diaclases com orientações N-S e NNE-SSW no sitio arqueológico Toca das Pedrinhas Pintadas e adjacências (Fonte: earth.google.com.br).

Na direção, a nordeste que é a direção do lineamento principal das cuestas do Parque Nacional Serra da Capivara, nas imediações do sitio arqueológico "caldeirão dos Rodrigues", se verifica um sistema de diaclases principal de WSW-ENE que acaba por encontrar, no setor 
leste do sitio, com outro sistema de diaclases de direção NW-SE (Figura 10). O encontro de diaclases quase perpendiculares e esforços com diferentes direções.

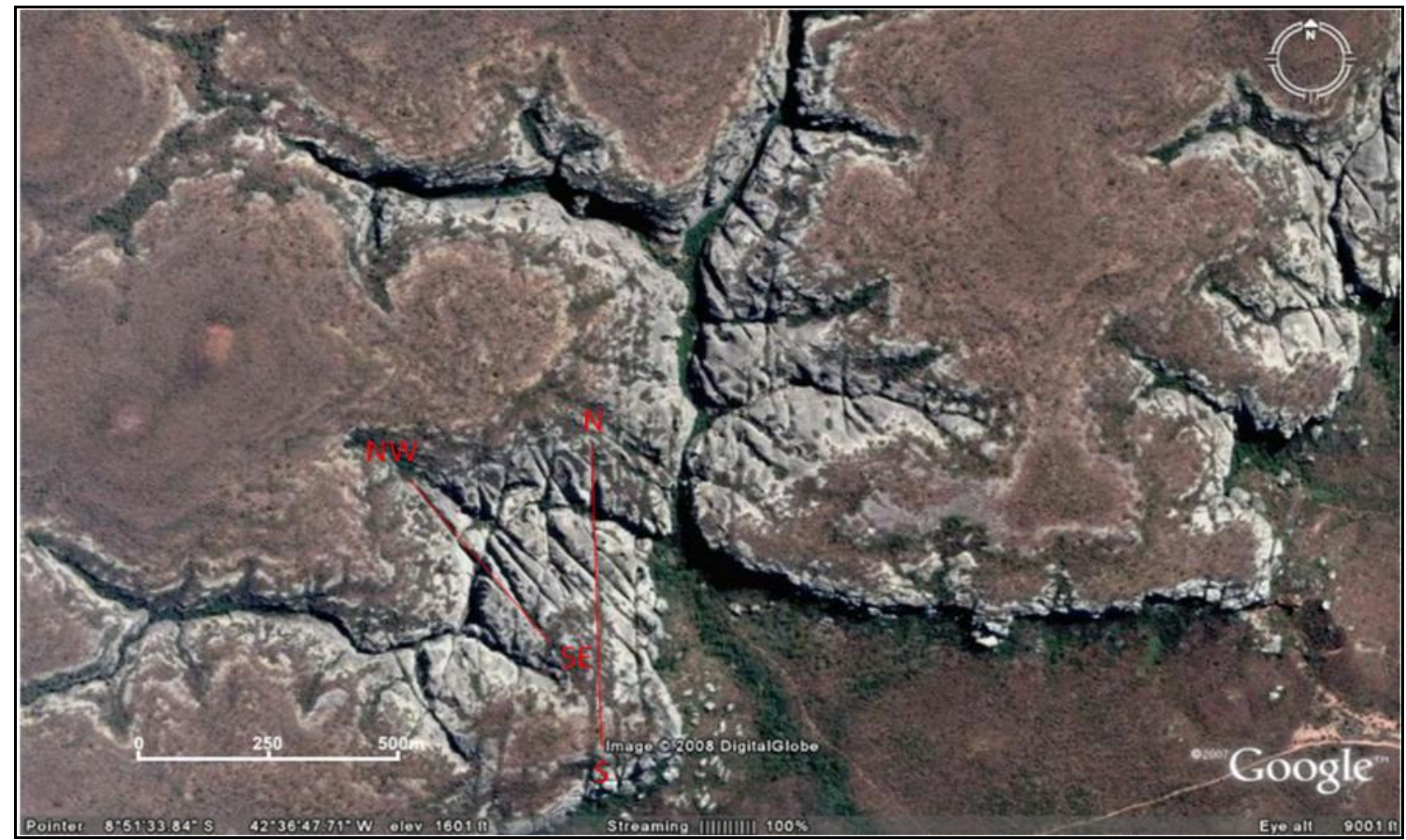

Figura 9 - Diaclases com orientações N-S e NW-SE no entorno do sitio arqueológico Toca dos Oitenta, evidenciando as tensões em diferentes direções (Fonte: earth.google.com.br).

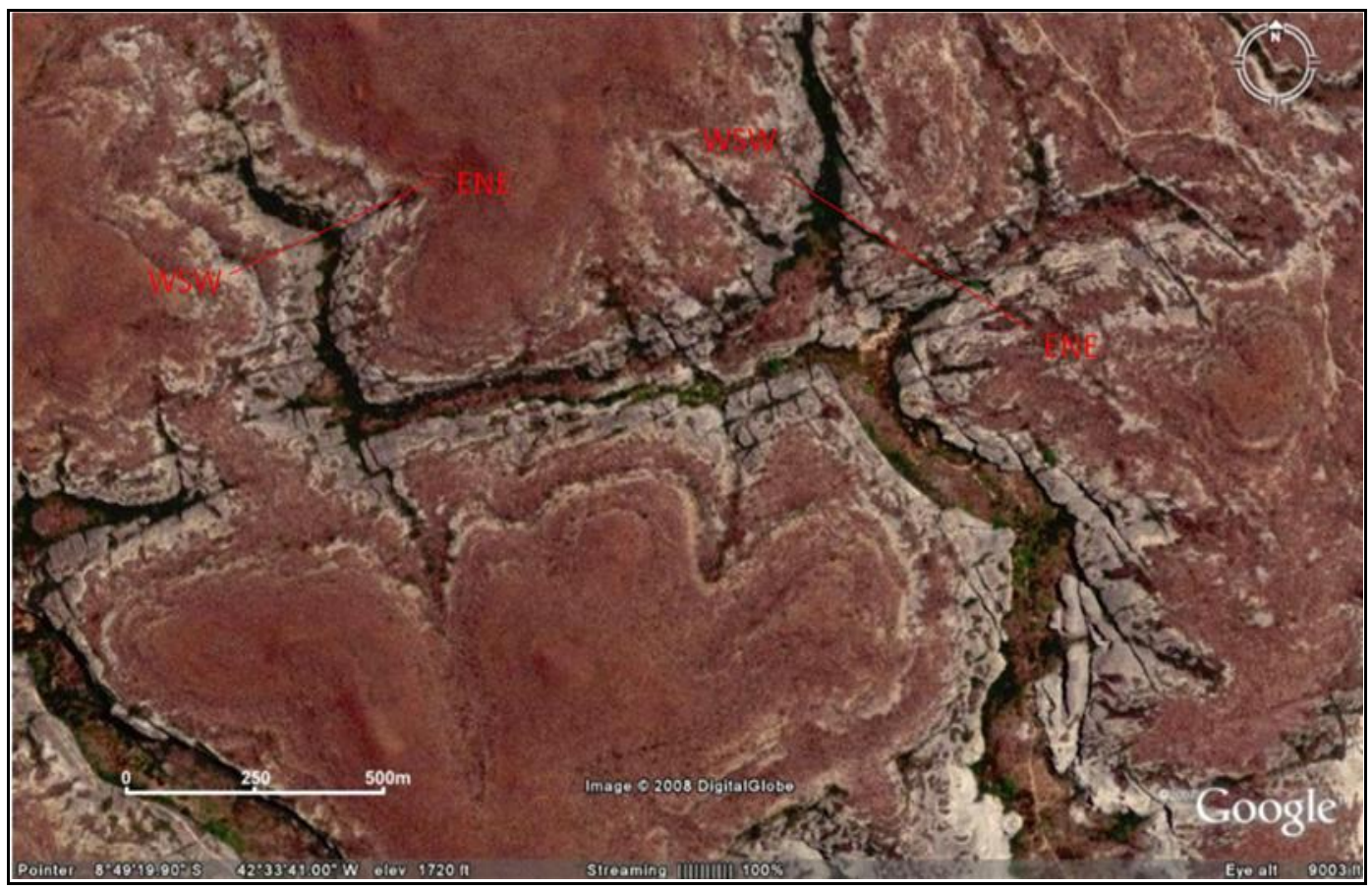

Figura 10 - Diaclases com orientações WSW-ENE interceptadas por diaclases com orientações NW-SE na região do sitio arqueológico Caldeirão dos Rodrigues (Fonte: earth.google.com.br). 
No setor nordeste em direção ao lineamento das cuestas da bacia do Parnaíba, se encontra

o Boqueirão da Pedra Furada, o principal e mais conhecido sitio arqueológico do parque (Figura 11).

Ao nordeste deste sitio se verifica um sistema de diaclases orientadas WSW-ENE, intersectadas por um sistema de diaclases predominantes nos arredores do sitio com direção NW-SE. Nas imagens de satélite desta área se nota com extrema nitidez estas diaclases condicionando de forma relevante, o modelado do relevo ruiniforme, inclusive a própria Pedra Furada, que evoluiu a partir de uma fratura de direção NW-SE, e depois, devido à erosão eólica diferencial, foi esculpido o buraco circular no centro que acabou por sugerir seu nome (Figura 3).

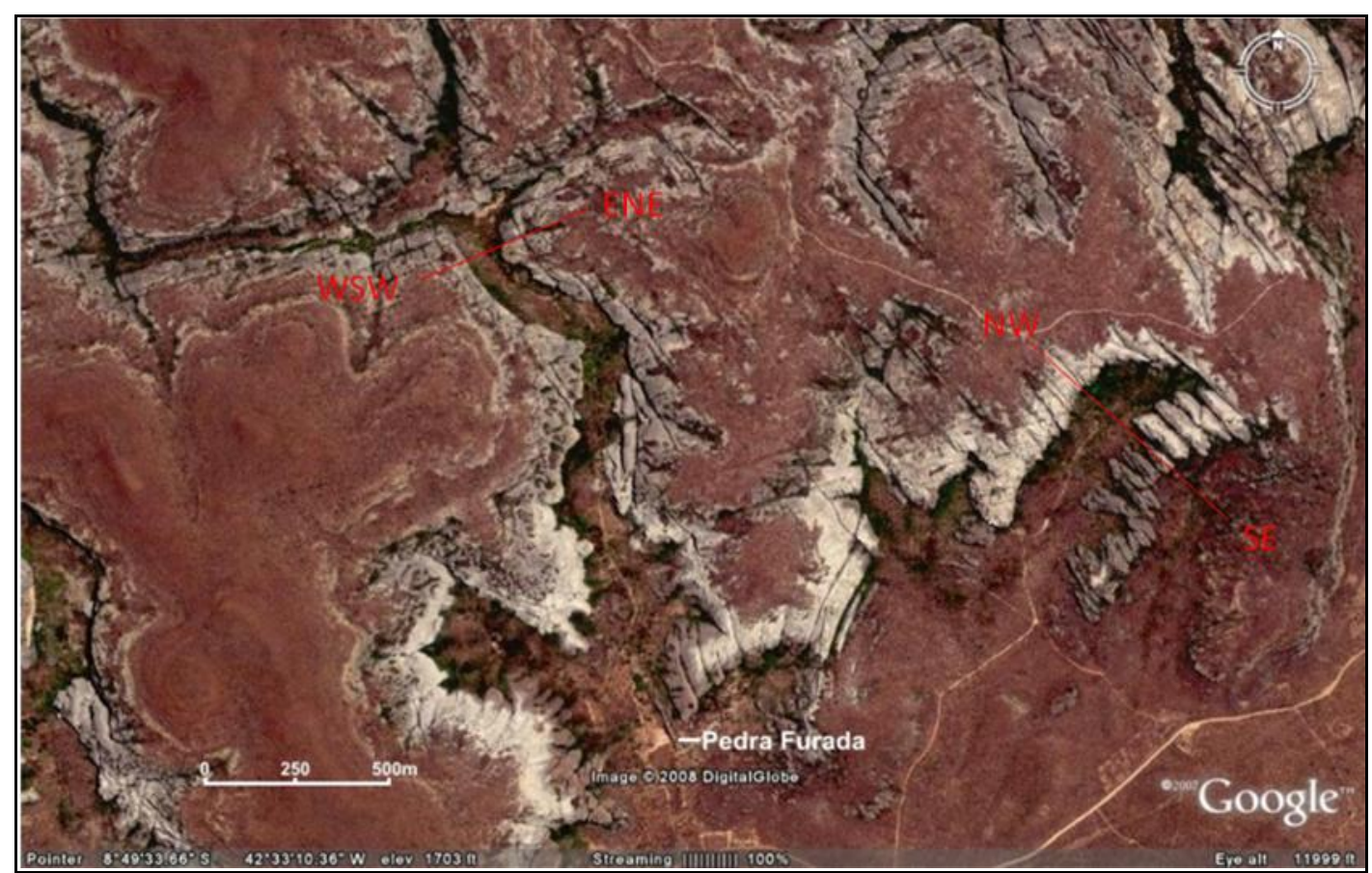

Figura 11 - Diaclases com orientações NW-SE intersecções por diaclases WSW-ENE nas imediações do boqueirão da Pedra Furada (Fonte: earth.google.com.br).

\section{CONSIDERAÇÕES FINAIS}

Os mapas temáticos confeccionados, assim como as imagens de satélite obtidas demonstram que o fator tectônico é predominante na evolução do modelo se pode analisar a formação do relevo ruiniforme, muito comum na borda sudeste do parque. As direções destas diaclases parecem aproveitar-se das falhas do embasamento cristalino PréCambriano que sustenta a bacia do Parnaíba. 
É inegável que estes sistemas de diaclases encontrados influência notoriamente na evolução morfológica de borda sudeste do parque, porque estas diaclases nas chuvas torrenciais obedecem a sua direção fomentando o poder erosivo da água como consequência uma evolução do modelado demasiadamente rápido.

O deságüe das águas pluviais ocorrem, preferivelmente, pelas fraturas onde o fluxo se torna mais concentrado e, portanto, com maior poder de erosão, dinamizando a evolução do relevo pela meteorização física. Quando as águas são represadas em porções dentro destas fraturas formando os chamados "caldeirões", e infiltrando pelos poros das rochas sedimentares e dissolvendo a formação, a meteorização química passa também a contribuir de forma acentuada na evolução do relevo.

Embora se encontrem fraturadas com distintas direções, há uma nítida predominância de fraturas de direção NW-SE, o que corrobora a idéia que grandes traços estruturais do embasamento Pré-Cambriano estão orientados nesta mesma direção e, possivelmente, reativados durante e depois da abertura do atlântico condicionam os traços estrutura da bacia do Parnaíba nesta área as direções encontradas para as fraturas também reforçam a ideia de esforços distintos na direção e na escala temporal, além de criar a hipótese da convergência dos lineamentos e falhas de direções diversas descritos anteriormente.

É primordial e indiscutível a influência destes sistemas de diaclases na evolução e configuração geomorfológica do Parque Nacional Serra da Capivara, apesar do correto entendimento da gênese destes esforços está longe de uma explicação convincente e única. O que este estudo demonstra que o fator tectônico estrutural não pode ser desconsiderado no Brasil nos estudos geomorfológicos.

\section{REFERÊNCIAS BIBLIOGRÁFICAS}

BRASIL. Ministério de Minas e Energia. CPRM: Mapa geológico do Estado do Piauí. Brasília: CPRM, 2006. 1. mapa color. Escala 1:100.000.

BRITO NEVES, B. B. O mapa geológico do nordeste oriental do nordeste do Brasil, escala 1/1.000.000. 1983. 177 f. Tese (Livre Docência) - Instituto de Geociências, Universidade de São Paulo, São Paulo, 1983.

CÂMARA, G.; DAVIS. C.; MONTEIRO, A. M.; D'ALGE, J. C. Introdução à Ciência da Geoinformação. São José dos Campos: INPE, 2001. 
GUERRA, A. T.; TEIXEIRA GUERRA, A. J. Novo dicionário geológico-geomorfológico. Rio de Janeiro: Bertrand Brasil, 1997.

HERZ, R.; DE BIASI, M. Critérios e legendas para macrozoneamento costeiro. Brasília: Comissão Interministerial para os Recursos do Mar. 1989.

LOCZY, L.; LADEIRA, E. A. Geologia estrutural e introdução à geotectônica. São Paulo: Edgard Blücher. Conselho Nacional de Desenvolvimento Científico e Tecnológico, 1980.

LOPES, E. S. S.; RIEDEL, P. S.; VIDOTTI, M.; MERINO, E. R. Análise de modelo numérico do terreno para modelos geomorfológicos. In: SIMPÓSIO NACIONAL DE GEOMORFOLOGIA. 2006. Goiânia. Anais... Goiânia: universidade Federal de Goiás. v. 2. p. 1-9. 2006.

PETRI, S.; FÚLFARO, V. J. Geologia do Brasil. São Paulo: T. A. Queiroz/EDUSP, 1983.

ROSS, J. L. S. Relevo brasileiro: uma nova proposta de classificação. Revista do Departamento de Geografia da FFLCH/USP, São Paulo, v. 4. 1985.

SAADI, A.; BEZERRA, F. H. R.; COSTA, R. D.; IGREJA, H. L. S; FRANZINELLI, E. Neotectônica da plataforma brasileira. In: SOUZA, C. R.; de; SUGUIO, K.; OLIVEIRA, A. M. dos S.; OLIVEIRA, P. E. de (Org.). Quaternário do Brasil. Ribeirão Preto: Holos, Editora, 2005. p. 211-234.

SADOWSKI, G. R.; CAMPANHA, G. A. C. Grandes falhas do Brasil continental. In: MANTESSONETO, V.; BARTORELLI, A.; CARNEIRO, C. D. R.; BRITO-NEVES, B. B. de (Org.). Geologia do continente sul-americano: evolução da obra de Fernando Flávio Marques de Almeida. São Paulo: Beca, 2004. p. 407-421.

SUGUIO, K. Geologia do Quaternário e mudanças ambientais: (passado + presente = futuro?). São Paulo: Paulo's Comunicações e artes gráficas, 1999.

SUGUIO, K. Dicionário de geologia sedimentar e áreas afins. Rio de Janeiro: Bertrand Brasil, 1998.

Artigo submetido em 12/02/2012.

Artigo aceito em 26/03/2012. 